DOI: $10.2478 / \mathrm{rrlm}-2018-0001$

\title{
Is galectin-3 a promoter of ventricular dysfunction?
}

\author{
Adrian Lupu ${ }^{1}$, Silvia Lupu ${ }^{*}$, Lucia Agoston-Coldea ${ }^{3}$ \\ 1. Iuliu Hatieganu University of Medicine and Pharmacy, Cluj Napoca, Romania \\ 2. University of Medicine and Pharmacy of Tirgu Mures, Romania \\ 3. 2nd Department of Internal Medicine, Iuliu Hatieganu University of Medicine and Pharmacy, \\ Cluj-Napoca, Romania
}

\begin{abstract}
Heart failure is nowadays a common condition associated with high mortality and increased healthcare-related costs. Over the years, the research on heart failure management has been extensive in order to better diagnose and treat the condition. Since the progression of left ventricular dysfunction is a consequence of myocardial inflammation, apopotosis, and fibrosis leading to myocardium remodelling, several molecules that are involved in the inflammation pathways have been explored as possible biomarkers for the condition. The study of biomarkers and their key roles in inflammation could allow early identification of patients with heart failure, improve prognostic assessment, and provide a target for future therapies. Among currently studied biomarkers, extensive research has been conducted on galectin-3, a galactoside-binding lectin, which is synthetised and secreted when cardiomyocytes and fibroblasts are submitted to mechanical stress. Accordingly, it has been hypothesised that galectin-3 could be a promoter of left ventricular dysfunction. Galectin-3 has been shown to mediate inflammation by several different pathways which are further detailed in the current review. Also, we aimed to provide a comprehensive overview of existing evidence on the utility of galectin-3 in clinical settings associated with heart failure.
\end{abstract}

Keywords: Galectin-3, biomarker, heart failure, dyspnea, ventricular dysfunction, ventricular remodelling

Received: 10 $0^{\text {th }}$ September 2017; Accepted: 10 th December 2017; Published: $15^{\text {th }}$ December 2017

\section{Introduction}

Heart failure (HF) is currently a major cause of morbidity and mortality worldwide, being associated with increased hospitalization rates and healthcare-related costs [1]. Myocardial injury, hemodynamic overload, genetic, neuro-hormonal changes and inflammatory processes contribute to myocardial remodelling and progression of left ventricular (LV) dysfunction [2]. The myocardial remodelling process begins by in- flammation, followed by fibrosis [3], myocardial hypertrophy [4], apopotosis and myocardial necrosis $[5,6]$, resulting in ventricular dysfunction. Traditional approaches to the diagnosis and treatment of HF rely on identifying the causes and on attempting to manage these causes, with favourable outcomes [7]. However, little progress has been made in terms of identifying a therapeutic strategy that targeted fibrosis directly. Despite the current lack of such treatment, studies have

*Corresponding author: Silvia Lupu, University of Medicine and Pharmacy of Tirgu Mures, Romania E-mail: silvia.lupu@umftgm.ro 
been made and data has begun to pool regarding certain factors that seem to be involved in the development of fibrosis and HF. Such molecules are currently in use or under study as biomarkers of HF, contributing to early diagnosis of the condition, beyond the already aknowledged N-terminal pro-Brain-type Natriuretic Peptide (NT-proBNP) [8]. Galectin-3 has been proposed as a biomarker of HF due to its active involvement in the inflammatory [9] and pro-fibrotic process $[10,11]$, since its synthesis and secretion are triggered by mechanical stress on cardiomyocytes and fibroblasts. The possibility of inhibiting these links in the pathophysiological process of fibrosis development maintains the interest of researchers and clinicians willing to stop or even prevent the development and progression of HF [12-15].

The aim of this review is to provide a general outlook on the experimental and clinical data which are currently available regarding the role of galectin-3 in HF.

\section{Galectin-3: Biological background and function}

Among the members of this lectin family, galectin-3 has been the most extensively studied; galectin-3 has been shown to mediate several processes, including cell adhesion, migration, survival, death, and differentiation [16]. Galectins bind $\beta$-galactose-containing glycoconjugates and have similar primary structures in their carbohydrate recognition domains (CRDs) [17]. At least 15 members of the galectin familiy have been identified in animal experiments so far and most of them (galectin 1-4, 7-9, 12-13) have also been found in humans. The galectin family includes three subtypes: (i) prototype, (ii) chimera, and (iii) tandem repeat group, differentiated by the number and organization of CRDs [18]. Galectin-3 is a chimeric, soluble $\beta$-galactoside binding lectin from the galectin family, with three distinct domains: a NH2-terminal domain, a proline-rich collagen-alpha-like domain, and a $\mathrm{COOH}$-terminal domain containing the CRD [16, 17, 18, 19]. The C-terminal domain allows binding to carbohydrate ligands, such as $\mathrm{N}$-acetyllactosamine, while the $\mathrm{N}$-terminal domain allows the formation of oligomers and interaction with cell mebranes or extracellular receptors, such as those found on macrophages or collagen IV, respectively [20,21].

Galectin-3 is found under different forms: 1) the primary form contains a polypeptidic chain of 250 aminoacids; the N-terminal domain has 120 aminoacids and allows the formation of oligomers, as well as the expression of the molecule on the cell membrane [20]; the collagen-alpha-like medial sequence includes proline and glycine, and can be cleaved by metaloproteinases [22]; the C-terminal domain contains 130 aminoacids [23]; 2) in the secondary form, CRD is organized as a $\beta$-pleated sheet, with antiparallel organization of polypeptidic chains which render it flexible and resilient to stretch [24]; 3) a globular tertiary form; 4) a quaternary form that may be either mono- or multimeric according to the concentration: when concentrations are low, monomers are more likely to occur, promoting intercellular adhesion, by binding and blocking integrins on other cells; when concentrations are higher, multimers are formed, mediating intercellular adhesion.

Galectin-3 is coded by the LGALS3 gene on chromosome 14 [25] and can be found in different compartiments in the body, and under different forms. Galectin-3 can be found in several species, in the intracellular, as well as in the extracellular space [26]. These biomarkers are mostly found in the cytoplasm [27], but may also cross cellular and intracellular membranes, thus being able to enter the nucleus or mitochondria, to be expressed on the cell membrane or to pass into the extracellular space, and, subsequently, in the systemic circulation [27,28]. Cytosol galec- 
tin-3 inhibits apoptosis, and can be expelled from the cell by exocytosis, circumventing the Golgi apparatus and the endoplasmic reticulum, further having a tendency to bind to several extracellular matrix proteins, such as fibronectin, tenascin and laminin [21]. In the nucleus, galectin-3 is involved in splicing and cell proliferation, while when expressed on the surface of the cells, it has the ability to modulate cell survival and mRNA splicing [29].

Galectin-3 mediates interactions between cells and between cells and the extracellular matrix, binds to glicans and modulates intracellular signaling pathways, leading to cell activation [30], proliferation and apoptosis [31]. Moreover, galectin-3 has an important proadhesion role [32], acting as a ligand for glucose, lipids and mycrobiological factors, including endotoxins [33]. Also, it has chemotactic properties, being involved in the recruitement of monocytes and macrophages, neutrophile adhesion, and the release of pro-inflammatory cytokines from leukocytes and mastocytes [34], as well as the phagocytic clearance of apoptotic neutrophiles [35].

Galectin-3 synthesis occurs in several types of cells, such as fibroblasts, granulocytes, tumoral cells and microglia. According to the synthesis site, galectin-3 is involved in organ-specific pathophysiology, modulating fibrogenesis $[10,11]$ and inflammation [9] at these sites.

\section{Galectin-3: role in cardiac remodelling}

Galectins seem to have a wide range of biological roles, and evidence begins to pool that they are involved in inflammatory processes in several tissues and organs, including the heart.

Galectin-3 induces cardiac remodelling by several processes including myocardial cell apoptosis, hypertrophy, inflammation and fibrosis, leading to myocardial dysfunction (Figure 1).

\section{Cell Apoptosis}

Apoptosis preserves the balance between proliferation and turnover in all living tissues, including the myocardium. At this level, when cell stress occurs, galectin- 3 activates the proapoptotic c-Jun-N-terminal kinase $1 / 2$, triggering cell apoptosis by increasing deoxinucleotidil transpherase terminal 2'-deoxyuridine 5'-triphosphate [36]. Extracellular apoptosis induced by galectin-3 in activated T cells induces mithochondrial apoptosis, cytchrome $\mathrm{C}$ release and the activation of caspase-3 [37]. Endogenous galectin-3 is involved in apoptotic signalling pathways regulated by the activated caspase- 8 and the pro-apoptotic activity of the mitochondria, inducing cell death [37]. The ability of galectin-3 to induce $\mathrm{T}$ cell apoptosis is dependent on its cytosolic levels [37].

\section{Cellular mechanisms}

Cell adhesion is necessary for maintaining the three-dimensional structure and normal function of the heart. Galectin-3 promotes neutrophil and laminin adhesion and mediates IL-8 synthesis and L-selectin shedding to induce appropriate immune responses [38]. Also, galectin-3 can bind monocytes to laminin and contribute to their activation, as well as up-regulate the expression of other adhesion mollecules and increase cell adhesion to fibronectin [39]. Further studies have shown that endogenous galectin-3 favours cell adhesion to collagen IV, while exogenous galectin-3 accelerates epitelial healing processes and promotes cell migration [39].

\section{Myocardial inflammation}

Acute myocardial inflammation is a normal defensive response to lesions, irritation and infections, while chronic inflammation is associated with deleterious effects. Chronic inflammation occurs either due to failure of acute inflammation processes in completing the healing process, or by persistence of the harming agent. 
Galectin-3 is an inflammatory protein which activates and promotes macrophage migration [40]. Galectin-3 mollecules expressed by eosinophils bind to immobilized galectin-3 and type 1 vascular adhesion cells [40]. In patients with $\mathrm{HF}$, increased galectin-3 expression promotes neutrophile recruitement at the inflammation site [40].

\section{Myocardial fibrosis}

Myocardial fibrosis is considered irreversible in a wide range of cardiovascular diseases, including overt HF [41]. Recent studies have shown that galectin-3 is involved in the proliferation and differentiation of myofibroblasts that further stimulate collagen synthesis. Galectin-3 expression is elevated in homozygote TGRmRen2-27 transgenic rats who develop HF and is colocalized on the surface of activated mac- rophages, being able to bind to fibroblasts and the extracellular matrix [42]. Moreover, the proliferation of fibroblasts induced by recombinant galectin-3 leads to collagen synthesis [42]. Galectin-3 seems to be involved in myocardial inflammation by both macrophage activation and by increased proliferation of extracellular matrix producing cells.

To conclude, cytosolic, nuclear and circulating galectin-3 is involved in preserving the balance between proliferation and apoptosis, thus promoting the normal turnover of several types of cells, including the myocytes. Moreover, galectin-3 promotes normal healing after acute inflammation. However, when cells are chronically submitted to stress, galectin-3 related pathways promote the development of myocardial hypertrophy and fibrosis. (Figure 1)

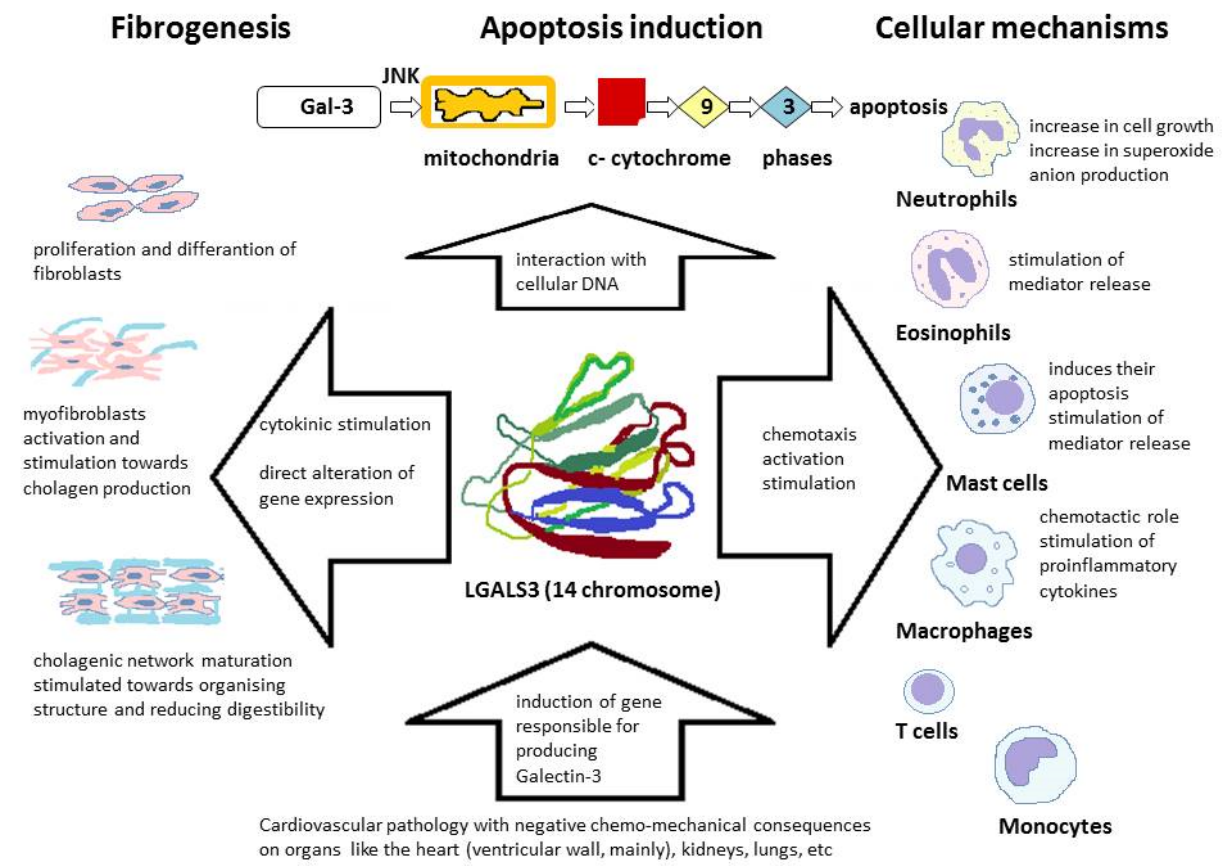

Figure 1. Galectin-3 in cardiac remodelling - mechanically-induced stress on myocytes and fibroblasts

triggers increased synthesis and secretion of galectin-3. Further, galectin-3 modulates fibrogenesis by cytokine stimulation and direct alteration of gene expression; induces apoptosis by interaction with cellular DNA; and contributes to the chemotaxis, activation and stimulation of all white blood cells. 


\section{Galectin-3 in experimental studies}

Several experimental studies have demonstrated the involvement of galectin-3 in inflammation, fibrogenesis and the development of vascular and myocardial remodelling and dysfunction. Also, some researchers attempted to limit or prevent myocardial fibrosis by targeting galectin-3.

Sharma et al, for instance, showed that repeated intrapericardial infusions with galectin-3 lead to collagen accumulation, myocardial remodelling and ventricular dysfunction in previously healthy rodents [9].

Also, in a relatively recent study, both wildtype and galectin-3 knock-out mice were submitted to angiotensin II infusions and transverse aortic constriction for 28 days in order to induce cardiac remodelling. Mice in both groups developed myocardial hypertrophy, but only wild-type mice had evidence of myocardial fibrosis, while galectin-3 knock-out mice did not. Accordingly, the authors studied the effects of a galectin-3 inhibitor, $\mathrm{N}$-acetyl lactosamine, on both cultured cells and rats, showing less myocardial remodelling after treatment [43]. Moreover, Frenay et al. demonstrated the protective effect of $\mathrm{N}$-acetyl lactosamine on renal function in hypertensive rats, showing decreased proteinuria and plasma creatinine, as well as lower systolic blood pressure values, despite persistently elevated matrix remodelling factors [44].

In another study, arterial hypertension was induced in both wild-type and galectin-3 knockout Wistar rats by the administration of aldosterone and salt, but only the wild-type rats had increased aortic galectin-3 expression, inflammation, and collagen type I. These effects seemed preventable or reversible if citrus pectin - a galectin-3 inhibitor - and/or spironolactone were administered. Aortic mRNA analysis revealed that interleukin-6 synthesis was considerably diminished by spironolactone and completely blocked by citrus pectin [45]. These results may provide a pathophysiological background for the already documented reverse-remodelling effects of spironolactone in human patients with HF and raise hope for potential therapeutic effects of citrus pectin.

Also, myocardial hypertrophy and cardiac remodelling with increased fibrosis were associated with high galectin-3 levels in rats with induced autoimmune myocarditis, and were shown to respond to treatment with T-3999, a novel phenylpyridazinone [46].

Other animal studies explored the pro-inflammatory potential of galectin-3 in other tissues. For example, Dvorankova et al. demonstrated that in vitro administration of recombinant galectin-3 can trigger activation of myofibroblasts, with subsequent production of extracellular matrix, a finding which could be used in tissue engineering and wound repair [47]. Henderson et al. explored the involvement of galectin-3 in the development of liver fibrosis, showing that myofibroblast activation and procollagen (I) expression is markedly reduced when the galectin-3 gene is supressed [48]. Also, kidney fibrosis is unlikely to occur in the absence of galectin-3 [49].

\section{Galectin-3 in clinical studies}

During the last few years, galectin-3 has raised the interest of clinical researchers, and, accordingly, several clinical studies were conducted in order to explore the use of galectin-3 in clinical practice for the purpose of diagnosis, risk-stratification, monitoring the response to therapy or establishing prognosis (Table 1).

\section{Diagnostic use}

The diagnostic use of galectin-3 has been explored in several large trials, as well as smaller studies, yielding somewhat conflicting results. 


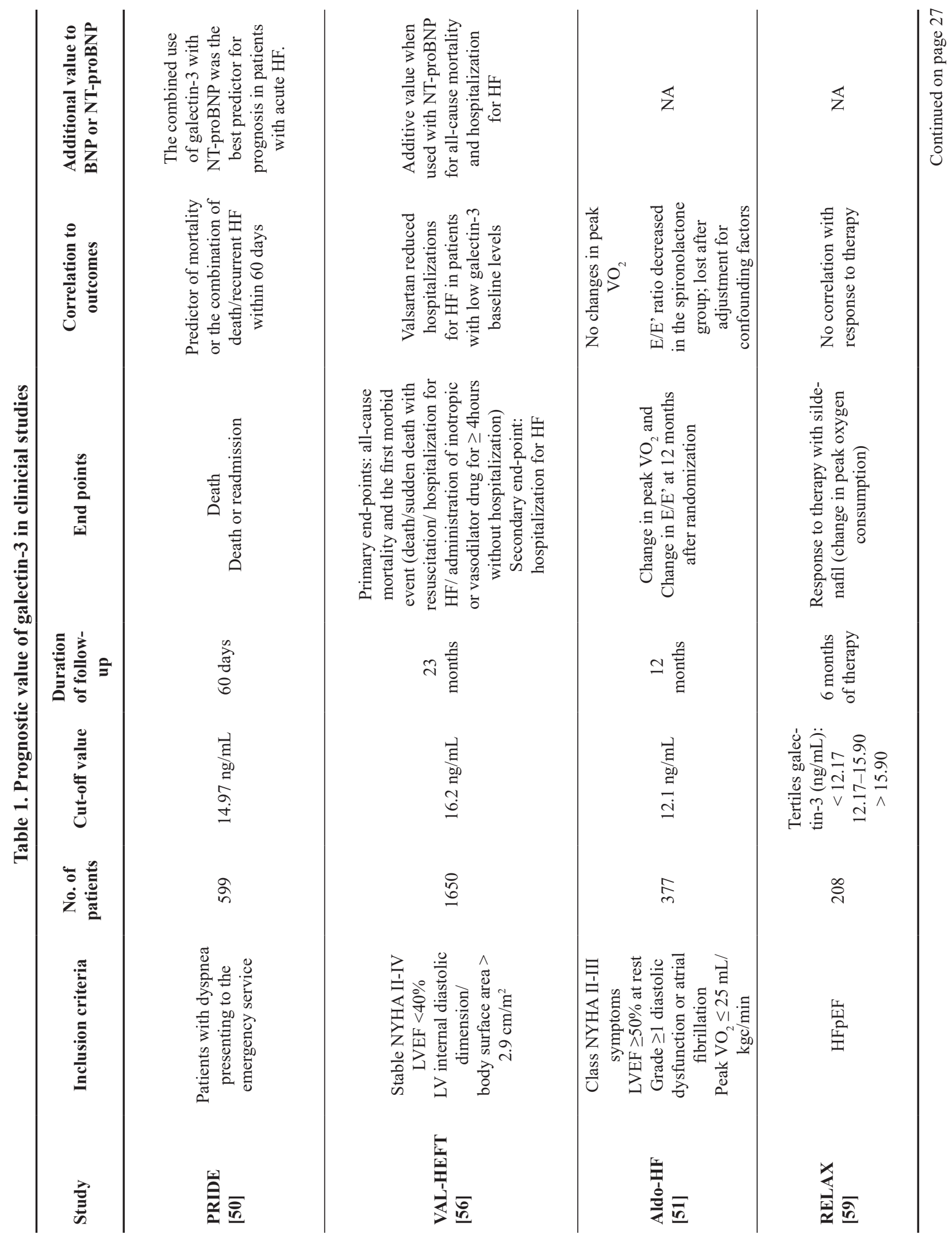




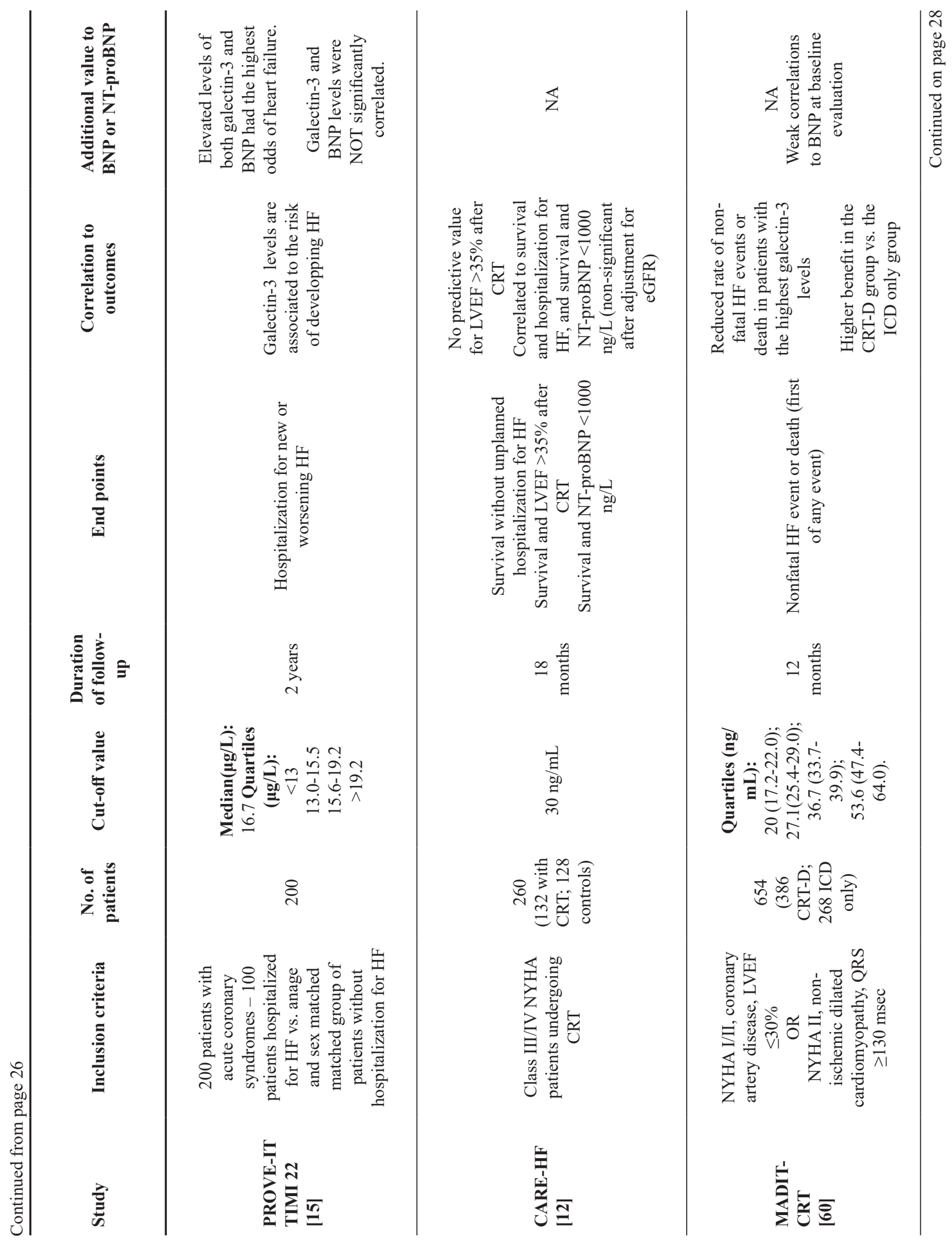




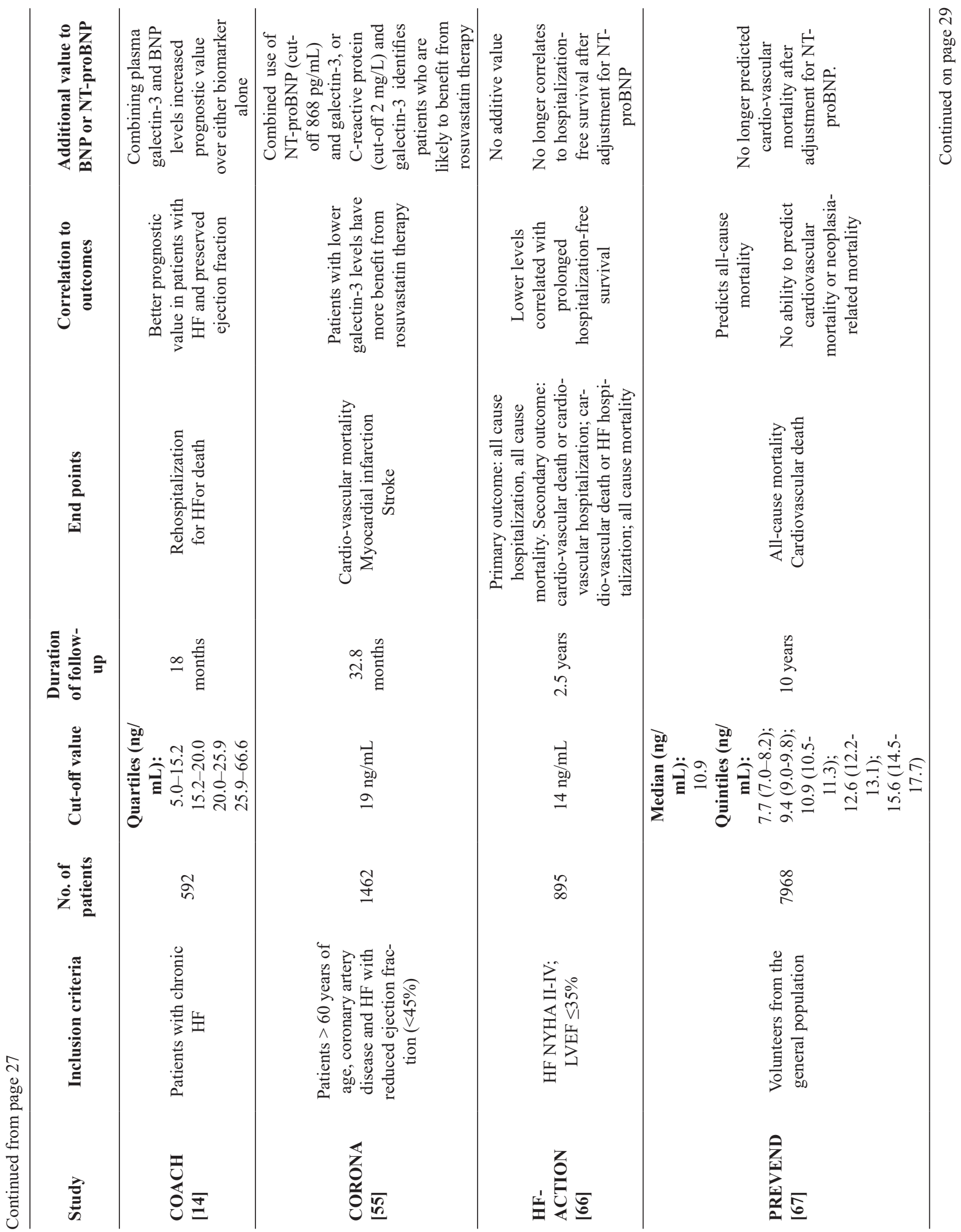




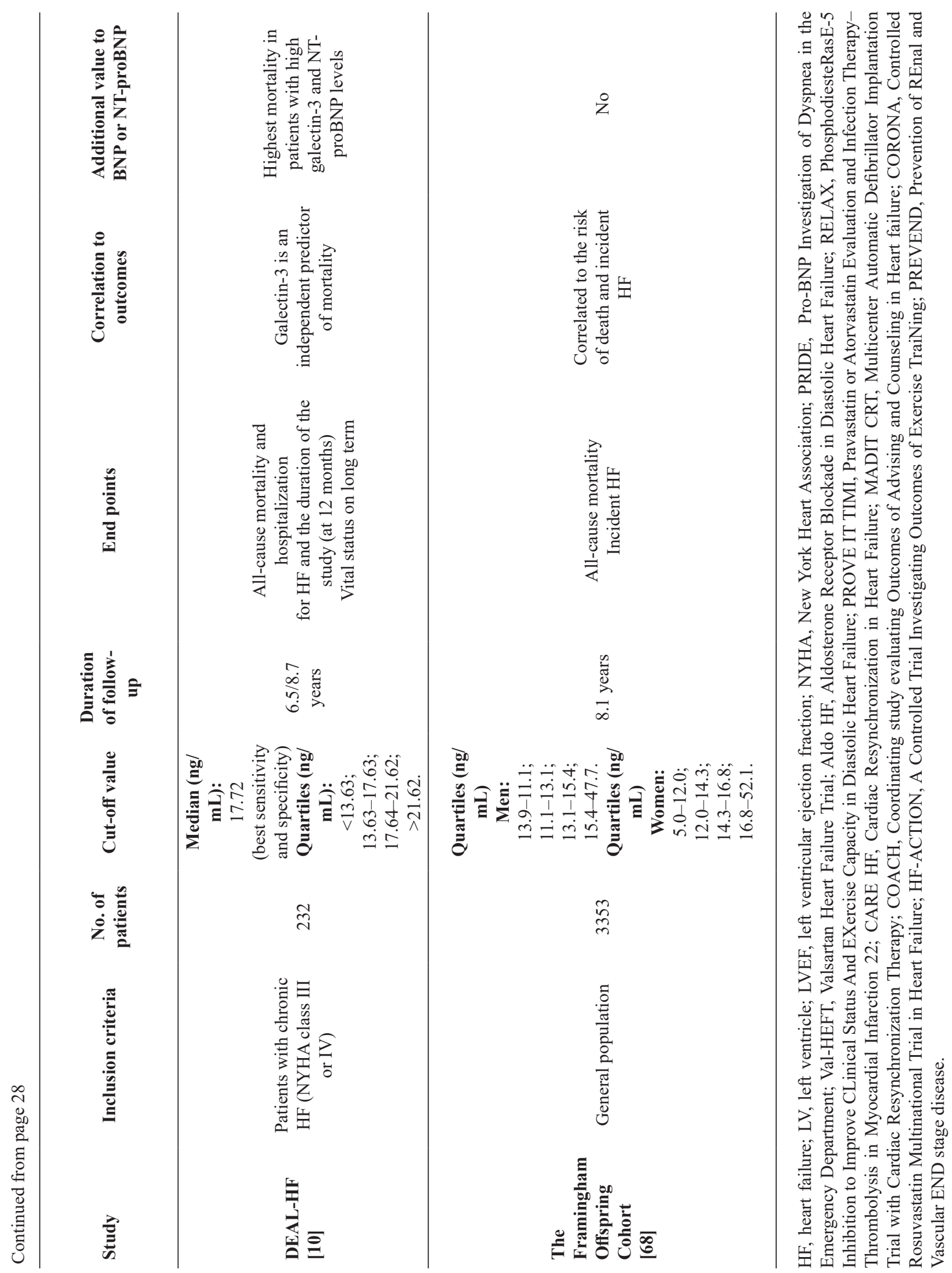


Valuable data have been obtained from the PRIDE (Pro-BNP Investigation of Dyspnea in the Emergency Department) trial, which tested the diagnostic and prognostic abilities of NT-proB$\mathrm{NP}$, galectin-3 and apelin in acute HF. In this trial, galectin-3 was proved superior to apelin, but inferior to NT-proBNP for identifying acute HF, despite having better prognostic value [50].

In the Aldo-DHF (Aldosterone Receptor Blockade in Diastolic Heart Failure) trial, focused on patients with HF with preserved ejection fraction ( $\mathrm{HFpEF}$ ), galectin-3 was inversely correlated to exertion capacity, assessed by the 6-minute walk test distance and peak oxygen consumption, the quality of life, assessed by the Short Form 36, and worse outcomes [51].

In the research conducted by Mueller et al, comparing the ability of BNP, sST2 and galectin-3 for identifying HF patiens, the latter performed the least well, having the lowest area under the curve, and did not provide any additional diagnostic value to BNP [52].

Mohammed et al. explored the diagnostic value of galectin-3 in a pediatric population with $\mathrm{HF}$ and acyanotic congenital heart disease and demonstrated statistically significant correlations between galectin-3 levels and HF severity. Their analysis yielded $83.3 \%$ sensitivity and $63.3 \%$ specificity for predicting HF, as well as significant direct correlations to left atrial and LV diameters or pulmonary artery pressures; negative correlations to the LV ejection fraction (LVEF) and shortening fraction also emerged [53]. In this study, however, acknowledged biomarkers of HF such as BNP or NT-proBNP have not been used and, therefore, it is not known whether galectin-3 could be superior or provide any additional value to conventional biomarkers.

Considering the results of these studies, galectin-3 is not reliable enough to identify patients with HF and does provide significant additional diagnostic value when used in combination with NT-proBNP.

\section{Impact of medical therapy on galectin-3 levels}

Correlations between galectin-3 and medical, interventional or device therapy outcomes have been approached in some large studies.

In the GISSI-HF (Gruppo Italiano per lo Studio della Sopravvivenza nell'Insufficienza cardiaca) [54] and CORONA (Controlled Rosuvastatin Multinational Trial in Heart Failure) trials [55] patients with HF did not seem to benefit from rosuvastatin therapy, beyond a reduction in the rate of hospitalization [55]. However, Gullestad et al. analyzed a subgroup from the CORONA trial and showed that selected patients with low levels of galectin-3 ( $<19$ pg/mL) responded well to rosuvastatin therapy, having lower cardiovascular mortality, myocardial infarction or stroke rates, and that benefits were highest in patients who had both low galectin-3 and NT-proBNP, or C-reactive protein levels [13].

Low galectin-3 levels also emerged as a good predictor of response to valsartan therapy in a subgroup analysis of 1650 patients from the Val-HEFT (Valsartan Heart Failure Trial) trial, independently of any other factors, including NT-proBNP levels. In this study, patients with galectin-3 levels lower than the median value of $16.2 \mathrm{ng} / \mathrm{mL}$ had significantly fewer hospitalizations for HF, while those with higher galectin-3 levels did not benefit at all from valsartan therapy [56].

By contrast, galectin-3 levels did not predict response to either spironolactone [57] or sildenafil [58] therapy in patients with HFpEF. Considering the fact that spironolactone has not been proved to influence outcomes in HFpEF patients beyond reducing hospitalization for HF and increasing the risk of hyperkaliemia [59], and the use of sildenafil in clinical practice is not endorsed by current HF guidelines, the importance of these findings is limited. 


\section{Galectin-3 and device-based therapy}

Data regarding the utility of galectin-3 in patients with cardiac resynchronization therapy (CRT) has also begun to pool. Interestingly, in a substudy of the MADIT-CRT (Multicenter Automatic Defibrillator Implantation with Cardiac Resynchronization Therapy) trial on patients with New York Heart Association (NYHA) class I/II undergoing CRT-D, higher levels of galectin-3 at baseline were associated with better outcomes (lower rate of non-fatal HF events or death) [60]. In this cohort, higher galectin-3 levels may suggest the presence of metabolically active myocardial fibrogenesis, that is likely to regress after CRT, leading to reverse remodelling, thus explaining the higher benefit in the increased galectin-3 levels quartile.

By contrast, in the CARE-HF study, higher galectin-3 levels were associated with worse outcomes, but, in this trial, patients were included if they had NYHA III-IV symptoms [12] and might have been beyond active inflammation.

In a relatively small study of 55 patients with advanced HF who received circulatory support devices (LV assist devices or total artificial hearts), galectin-3 levels were higher than in healthy volunteers, and were not significantly changed in the critically ill patients after a month of follow-up [61]. However, higher levels of galectin-3 were correlated with increased mortality after LV assist device implantation [61].

These findings were further confirmed in another study on 151 patients who received a LV assist device [62].

In the study by Cormilas et al, galectin-3 levels were measured in patients with either stable HF (defined as class NYHA I-III) or severe (class IV NYHA) HF, among whom 63 received a LV assist device, and 23 were explanted during the follow-up period; the study also included 85 patients who had a heart transplant. In this study, galectin-3 levels were correlated to increased HF severity and were associated with lower sur- vival after LV assist device placement, as well as with a higher incidence of coronary allograft vasculopathy after transplantation. Moreover, in this research, galectin-3 levels were lower after transplantation and higher after LV assist device explantation, suggesting a deleterious effect of the latter, probably related to the progression of inflammation in this setting [63].

\section{Prognostic value in heart failure}

\section{Short term prognosis}

The short-term prognostic value of galectin-3 was proved in the PRIDE trial, which showed an increased area under the curve for mortality at 60 days, even by comparison with NT-proBNP. However, prognosis was best assessed when both biomarkers were used [64].

In a recent study, galectin-3 levels were associated with worse prognosis after transcatheter aortic valve implantation at 30 days, but also on the long-term [65].

In the study by Mueller et al., galectin-3 predicted one year all-cause mortality as accurately as BNP and soluble ST2 in patients with acute HF. The combined use of every two biomarkers did not improve the prognostic ability for allcause mortality at one year [52].

\section{Medium term prognosis}

In the COACH (Coordinating study evaluating Outcomes of Advising and Counseling in Heart failure) trial, 592 patients with different degrees of HF were included, and a combined primary end-point of all cause mortality and HF hospitalization was followed. Galectin-3 levels at 6 months did not provide any additional value to baseline levels for prognostic purposes, suggesting that a single determination may be sufficient. In addition to that, the combined use of galectin-3 and NT-proBNP provided incremental prognostic value to either biomarker alone. Also, galectin-3 was signficantly higher in 
patients with HFpEF (defined as LVEF $>40 \%$ ), by comparison with patients with reduced LVEF, and might therefore be of a particular use in this category [14].

Moreover, in the CARE-HF (Cardiac Resynchronization in Heart Failure) trial, increased galectin-3 levels at enrollement predicted mortality and HF hospitalization in patients with IIIIV NYHA class HF, reduced LVEF and ventricular dyssynchrony [12].

The ability of galectin-3 to predict outcomes in patients with acute coronary syndromes was evaluated in a nested case-control study on 100 patients from the TIMI 22 (Pravastatin or Atorvastatin Evaluation and Infection Therapy Thrombolysis In Myocardial Infarction 22) trial. These patients were followed for 2 years and the main finding was that increased galectin-3 levels in the acute setting were associated with the development of HF in patients with acute coronary syndromes [15].

The HF-ACTION (A Controlled Trial Investigating Outcomes of Exercise TraiNing) trial was conducted on 885 chronic HF patients with reduced ejection fraction (HFrEF) who were followed for 2.5 years. In this trial, galectin-3 levels correlated with the NYHA class, maximum oxygen consumption, systolic blood pressure and the risk for hospitalization or allcause mortality, in univariate analysis; however, the correlation was lost in multivariate analysis, when adjustments for NT-proBNP levels were made [66].

\section{Long-term prognosis}

Several studies also approched the long-term prognostic value of galectin-3.

Among these, the PREVEND (Prevention of REnal and Vascular END stage disease) trial, performed on healthy volunteers who were followed over 10 years, showed that galectin-3 was an independent predictor of death of cardiovascular causes [67].
The Framingham Offspring Cohort included 3,353 patients who were followed-up for 8.1 years; in these patients, higher galectin-3 levels at enrollement were associated with an increased risk for HF, even after adjustment for BNP and clinical variables. Also, galectin-3 levels were associated with increased all-cause mortality [68]. In the study by Shah et al., elevated galectin-3 levels were also associated with increased mortality at 4 years [54].

Similarly, in the DEAL-HF trial on 232 NYHA III/IV HF patients, survival was significantly higher in the group with lower galectin-3 levels $(<17.72 \mathrm{ng} / \mathrm{mL})$, during the 6.5 years follow-up [10]. After extending the follow-up period to 8.7 years, galectin-3 levels were positively associated with the risk of death. However, in this study, galectin-3 levels were correlated to the progressive impairment of the renal function, rather than to parameters of LV remodelling such as increased end-diastolic volumes [10]. (Table 1)

\section{Confounding factors}

The study of biomarkers of HF has among its aims the identification of a biomarker with high specificity that would not be significantly influenced by co-morbidities. Data regarding galectin-3 suggests, however, that it can be altered by several other factors [13] [51] [61] [63]. Among possible confounders, the most solid evidence was gathered regarding the impaired renal function [13] [51] [61] [63]. Beside the renal function, other confounders have been identified, including older age, female gender, hypertension, body mass index, or prevalent coronary heart disease [13] [68].

\section{The value of galectin-3 in clinical practice. Future perspectives}

Galectin-3 is currently one of the most widely investigated biomarkers for cardiovascular 
disease, after BNP and NT-proBNP. However, the results that have been derived so far from experimental as well as clinical studies are somewhat conflicting and cannot provide any guidelines regarding the use of this molecule in clinical practice. Further research is needed before implementing the routine assessment of galectin-3 in cardiology, as well as in other specialities. Despite the present lack of convincing evidence from large trials, the study of galectin-3 remains a topic of interest for researchers and clinicians alike, as it does seem to have some diagnostic and prognostic value. Moreover, due to its role in inflammation, myofibrobalst activation, as well as in the synthesis and accumulation of collagen, galectin-3 may become a therapeutical target for preventing and limiting the development of myocardial fibrosis. Further, more extensive research is needed to reach that goal.

\section{Funding}

This work was partially supported by grant 4994/1/8.03.2016 from the Iuliu Hatieganu University of Medicine and Pharmacy of ClujNapoca.
Abbreviations
Aldo-HF, Aldosteron Receptor Blockade in Diastolic Heart Failure
CARE-HF, Cardiac Resynchronization in Heart Failure $\mathrm{COACH}$, Coordinating Study Evaluating Outcomes of Advising and Counseling in Heart Failure CORONA, Controlled Rosuvastatin Multinational Trial in Heart Failure CRDs, carbohydrate recognition domains CRT, cardiac resynchronization therapy GISSI-HF, Gruppo Italiano per lo Studio della Sopravvivenza nell'Insufficienza cardiaca $\mathrm{HF}$, heart failure HF-ACTION, A Controlled Trial Investigating

Outcomes of Exercise TraiNing HFpEF, heart failure with preserved ejection fraction

LV, left ventricle

LVEF, left ventricular ejection fraction

NT-proBNP, N-terminal pro-Brain-type

Natriuretic Peptide

NYHA, New York Heart Association

PREVEND, Prevention of Renal and Vascular

END stage disease

PRIDE, Pro-BNP Investigation of Dyspnea in the Emergency Department

PROVE IT TIMI 22, Pravastatin or Atorvastatin

Evaluation and Infection Therapy -

Thrombolysis In Myocardial infarction 22

$\mathrm{RV}$, right ventricle

Val-HEFT, Valsartan Heart Failure Trial

\section{References}

1. Ponikowski P, Voors AA, Anker SD, Bueno H, Cleland JG, Coats AJ, et al. 2016 ESC Guidelines for the diagnosis and treatment of acute and chronic heart failure: The Task Force for the diagnosis and treatment of acute and chronic heart failure of the European Society of Cardiology (ESC). Developed with the special contribution of the Heart Failure Association (HFA) of the ESC. Eur J Heart Fail. 2016 Aug; 18(8):891-975. DOI: 10.1002/ejhf.592

2. Kramer DG, Trikalinos TA, Kent DM, Antonopoulos GV, Konstam MA, Udelson JE. Quantitative evaluation of drug or device effects on ventricular remodeling as predictors of therapeutic effects on mortality in patients with heart failure and reduced ejection fraction: a meta-analytic approach. J Am Coll Cardiol. $2010 \mathrm{Jul}$; 56(5):392-406. DOI: 10.1016/j.jacc.2010.05.011

3. Gandhi MS, Kamalov G, Shahbaz AU, Bhattacharya SK, Ahokas RA, Sun Y, et al. Cellular and molecular pathways to myocardial necrosis and replacement fibrosis. Heart Fail Rev. 2011 Jan; 16(1):23-34. DOI: 10.1007/s10741-010-9169-3

4. Gattoni S, Røe ÅT, Aronsen JM, Sjaastad I, Louch WE, Smith NP, et al. Compensatory and decompensatory alterations in cardiomyocyte $\mathrm{Ca} 2+$ dynamics in hearts with diastolic dysfunction following aortic banding. J Physiol. 2017 Jun; 595(12):3867-89. DOI: 10.1113/ JP273879

5. Ibe W, Saraste A, Lindemann S, Bruder S, Buerke M, Darius H, et al. Cardiomyocyte apoptosis is related to left ventricular dysfunction and remodelling in dilated 
cardiomyopathy, but is not affected by growth hormone treatment. Eur J Heart Fail. 2007 Feb; 9(2):160-7. DOI: 10.1016/j.ejheart.2006.06.002

6. Hynes B, Kumar AH, O'Sullivan J, Klein Buneker C, Leblond AL, Weiss S, et al. Potent endothelial progenitor cell-conditioned media-related anti-apoptotic, cardiotrophic, and pro-angiogenic effects post-myocardial infarction are mediated by insulin-like growth factor-1. Eur Heart J. 2013 Mar; 34(10):782-9. DOI: 10.1093/ eurheartj/ehr435

7. Ohtani T, Mohammed SF, Yamamoto K, Dunlay SM, Weston SA, Sakata Y, et al. Diastolic stiffness as assessed by diastolic wall strain is associated with adverse remodelling and poor outcomes in heart failure with preserved ejection fraction. Eur Heart J. 2012 Jul; 33(14):1742-9. DOI: 10.1093/eurheartj/ehs 135

8. Wang TJ, Larson MG, Levy D, Benjamin EJ, Leip EP, Omland T, et al. Plasma natriuretic peptide levels and the risk of cardiovascular events and death. N Engl J Med. 2004 Feb; 350(7):655-63. DOI: 10.1056/NEJMoa031994

9. Sharma UC, Pokharel S, van Brakel TJ, van Berlo JH, Cleutjens JP, Schroen B, et al. Galectin-3 marks activated macrophages in failure-prone hypertrophied hearts and contributes to cardiac dysfunction. Circulation. 2004 Nov; 110(19):3121-8. DOI: 10.1161/01. CIR.0000147181.65298.4D

10. Lok DJ, Van Der Meer P, de la Porte PW, Lipsic E, Van Wijngaarden J, Hillege HL, et al. Prognostic value of galectin-3, a novel marker of fibrosis, in patients with chronic heart failure: data from the DEAL-HF study. Clin Res Cardiol. 2010 May; 99(5):323-8. DOI: 10.1007/s00392-010-0125-y

11. Zile MR, Jhund PS, Baicu CF, Claggett BL, Pieske B, Voors AA, et al. Plasma biomarkers reflecting profibrotic processes in heart failure with a preserved ejection fraction: data from the prospective comparison of ARNI with ARB on management of heart failure with preserved ejection fraction study. Circ Heart Fail. 2016 Jan; 9(1). pii: e002551. DOI: 10.1161/CIRCHEARTFAILURE.115.002551

12. Lopez-Andrès N, Rossignol P, Iraqi W, Fay R, Nuée J, Ghio S, et al. Association of galectin-3 and fibrosis markers with long-term cardiovascular outcomes in patients with heart failure, left ventricular dysfunction, and dyssynchrony: insights from the CAREHF (Cardiac Resynchronization in Heart Failure) trial. Eur J Heart Fail. 2012 Jan; 14(1):74-81. DOI: 10.1093/eurjhf/hfr151

13. Gullestad L, Ueland T, Kjekshus J, Nymo SH, Hulthe J, Muntendam P, et al. Galectin-3 predicts response to statin therapy in the controlled rosuvastatin multinational trial in heart failure (CORONA). Eur Heart J. 2012 Sep; 33(18):2290-6. DOI: 10.1093/eurheartj/ehs077

14. de Boer RA, Lok DJ, Jaarsma T, van der Meer P, Voors
AA, Hillege HL, et al. Predictive value of plasma galectin-3 levels in heart failure with reduced and preserved ejection fraction. Ann Med. 2011 Feb; 43(1):60-8. DOI: 10.3109/07853890.2010.538080

15. Grandin EW, Jarolim P, Murphy SA, Ritterova L, Cannon CP, Braunwald E, et al. Galectin-3 and the development of heart failure after acute coronary syndrome: pilot experience from PROVE IT-TIMI 22. Clin Chem. 2012 Jan; 58(1):267-73. DOI: 10.1373/ clinchem.2011.174359

16. Sharon N, Lis H. History of lectins: from hemagglutinins to biological recognition molecules. Glycobiology 2004 Nov; 14 (11):53R-62R. DOI: 10.1093/glycob/ cwh122

17. Barondes SH, Cooper DN, Gitt MA, Leffler H. Galectins. Structure and function of a large family of animal lectins. J Biol Chem. 1994 Aug; 269 (33):20807-10.

18. Boscher C, Dennis JW, Nabi IR. Glycosylation, galectins and cellular signaling. Curr Opin Cell Biol. 2011 Aug; 23 (4):383-92. DOI: 10.1016/j.ceb.2011.05.001

19. Miller MC, Ippel H, Suylen D, Klyosov AA, Traber PG, Hackeng T, et al. Binding of polysaccharides to humangalectin-3 at a noncanonical site in its carbohydrate recognition domain. Glycobiology. 2016 Jan; 26(1):8899. DOI: $10.1093 /$ glycob/cwv073

20. Barboni EA, Bawumia S, Henrick K, Hughes RC. Molecular modeling and mutagenesis studies of the N-terminal domains of galectin-3: evidence for participation with the $\mathrm{C}$-terminal carbohydrate recognition domain in oligosaccharide binding. Glycobiology. 2000 Nov; 10(11):1201-8. DOI: 10.1093/glycob/10.11.1201

21. Halimi H, Rigato A, Byrne D, Ferracci G, Sebban-Kreuzer C, Elantak L, et al. Glycan dependence of galectin-3 self-association properties. PLoS One. 2014 Nov; 9(11):e111836. DOI: 10.1371/journal.pone.0111836

22. Liu FT, Rabinovich GA. Galectins: regulators of acute and chronic inflammation. Ann N Y Acad Sci. 2010 Jan; 1183:158-82. DOI: 10.1111/j.1749-6632.2009.05131.x

23. Diehl C, Engström O, Delaine T, Håkansson M, Genheden S, Modig K, et al. Protein flexibility and conformational entropy in ligand design targeting the carbohydrate recognition domain of galectin-3. J Am Chem Soc. 2010 Oct; 132(41):14577-89. DOI: 10.1021/ ja105852y

24. Mazurek N, Conklin J, Byrd JC, Raz A, Bresalier RS. Phosphorylation of the beta-galactoside-binding protein galectin-3 modulates binding to its ligands. J Biol Chem. 2000 Nov; 275(46):36311-5. DOI: 10.1074/jbc. M003831200

25. Raimond J, Zimonjic DB, Mignon C, Mattei M, Popescu NC, Monsigny M, et al. Mapping of the galectin-3 gene (LGALS3) to human chromosome 14 at region 14q21-22. Mamm Genome. 1997 Sep;8(9):706-7. DOI: $10.1007 / \mathrm{s} 003359900548$

26. Gaudin JC, Mehul B, Hughes RC. Nuclear localisation 
of wild type and mutant galectin-3 in transfected cells. Biol Cell. 2000 Jan; 92(1):49-58. DOI: 10.1016/S02484900(00)88763-8

27. Davidson PJ, Davis MJ, Patterson RJ, Ripoche MA, Poirier F, Wang JL. Shuttling of galectin-3 between the nucleus and cytoplasm. Glycobiology. 2002 May 12(5):329-37. DOI: 10.1093/glycob/12.5.329

28. Liu FT, Patterson RJ, Wang JL. Intracellular functions of galectins. Biochim Biophys Acta. 2002 Sep; 1572(23):263-73. DOI: 10.1016/S0304-4165(02)00313-6

29. Patterson RJ, Haudek KC, Voss PG, Wang JL. Examination of the role of galectins in pre-mRNA splicing. Methods Mol Biol. 2015; 1207:431-49. DOI: 10.1007/978-1-4939-1396-1_28

30. More SK, Chiplunkar SV, Kalraiya RD. Galectin-3-induced cell spreading and motility relies on distinct signaling mechanisms compared to fibronectin. Mol Cell Biochem. 2016 May; 416(1-2):179-91. DOI: 10.1007/ s11010-016-2706-1

31. Hsu DK, Yang RY, Saegusa J, Liu FT. Analysis of the intracellular role of galectins in cell growth and apoptosis. Methods Mol Biol. 2015; 1207:451-63. DOI: 10.1007/978-1-4939-1396-1_29

32. Di Lella S, Sundblad V, Cerliani JP, Guardia CM, Estrin DA, Vasta GR, et al. When galectins recognize glycans: from biochemistry to physiology and back again. Biochemistry. 2011 Sep;50(37):7842-57. DOI: 10.1021/ bi201121m

33. Zhu W, Sano H, Nagai R, Fukuhara K, Miyazaki A, Horiuchi S. The role of galectin-3 in endocytosis of advanced glycation end products and modified low density lipoproteins. Biochem Biophys Res Commun. 2001 Feb; 280(4):1183-8. DOI: 10.1006/bbrc.2001.4256

34. Karlsson A, Christenson K, Matlak M, Bjorstad A, Brown KL, Telemo E, et al. Galectin-3 functions as an opsonin and enhances the macrophage clearance of apoptotic neutrophils. Glycobiology. 2009 Jan; 19(1):16-20. DOI: 10.1093/glycob/cwn104

35. Chen HY, Weng IC, Li CS, Wan L, Liu FT. Examination of galectins in phagocytosis. Methods Mol Biol. 2015; 1207:201-13. DOI: 10.1007/978-1-4939-1396$1 \_13$

36. Lin X, Yang P, Reece EA, Yang P. Pregestational type 2 diabetes mellitus induces cardiac hypertrophy in the murine embryo through cardiac remodeling and fibrosis. Am J Obstet Gynecol. 2017 Aug; 217(2):216.e1216.e13. DOI: 10.1016/j.ajog.2017.04.008

37. Fukumori T, Takenaka Y, Yoshii T, Kim HR, Hogan V, Inohara H, et al. CD29 and CD7 mediate galectin-3-induced type II T-cell apoptosis. Cancer Res. 2003 Dec 1; 63(23):8302-11.

38. Danella Polli C, Alves Toledo K, Franco LH, Sammartino Mariano V, de Oliveira LL, Soares Bernardes E, Roque-Barreira MC, et al. Monocyte migration driven by galectin 3 occurs though distinct mechanisms involv- ing selective interactions with the extracellular matrix. ISRN Inflamm. 2013 Feb; 2013:259256.

39. Gao X, Balan V, Tai G, Raz A. Galectin-3 induces cell migration via a calcium-sensitive MAPK/ERK1/2 pathway. Oncotarget. 2014 Apr; 5(8):2077-84. DOI: 10.18632/oncotarget.1786

40. Hsu DK, Chernyavsky AI, Chen HY, Yu L, Grando SA, Liu FT. Endogenous galectin-3 is localized in membrane lipid rafts and regulates migration of dendritic cells. J Invest Dermatol. 2009 Mar; 129(3):573-83. DOI: $10.1038 /$ jid.2008.276

41. Roubille F, Busseuil D, Merlet N, Kritikou EA, Rhéaume E, Tardif JC. Investigational drugs targeting cardiac fibrosis. Expert Rev Cardiovasc Ther. 2014 Jan; 12(1):111-25. DOI: 10.1586/14779072.2013.839942

42. Sharma UC, Pokharel S, van Brakel TJ, van Berlo JH, Cleutjens JP, Schroen B, et al. Galectin-3 marks activated macrophages in failure-prone hypertrophied hearts and contributes to cardiac dysfunction. Circulation 2004 Nov; 110(19):3121-8. DOI: 10.1161/01. CIR.0000147181.65298.4D

43. Yu L, Ruifrok WP, Meissner M, Bos EM, van Goor H, Sanjabi B, et al. Genetic and pharmacological inhibition of galectin-3 prevents cardiac remodeling by interfering with myocardial fibrogenesis. Circ Heart Fail. 2013 Jan; 6(1):107-17. DOI: 10.1161/CIRCHEARTFAILURE.112.971168

44. Frenay AR, Yu L, van der Velde AR, Vreeswijk-Baudoin I, López-Andrés N, van Goor H, et al. Pharmacological inhibition of galectin-3 protects against hypertensive nephropathy. Am J Physiol Renal Physiol. 2015 Mar; 308(5):F500-9. DOI: 10.1152/ajprenal.00461.2014

45. Calvier L, Miana M, Reboul P, Cachofeiro V, Martinez-Martinez E, de Boer RA, et al. Galectin-3 mediates aldosterone-induced vascular fibrosis. Arterioscler Thromb Vasc Biol. 2013 Jan; 33(1):67-75. DOI: 10.1161/ATVBAHA.112.300569

46. Kamal FA, Watanabe K, Ma M, Abe Y, Elbarbary R, Kodama M, Aizawa Y.A novel phenylpyridazinone, T-3999, reduces the progression of autoimmune myocarditis to dilated cardiomyopathy. Heart Vessels. 2011 Jan; 26(1):81-90. DOI: 10.1007/s00380-010-0018-Z

47. Dvořánková B, Szabo P, Lacina L, Gal P, Uhrova J, Zima T, et al. Human galectins induce conversion of dermal fibroblasts into myofibroblasts and production of extracellular matrix: potential application in tissue engineering and wound repair. Cells Tissues Organs. 2011; 194(6):469-80. DOI: 10.1159/000324864

48. Henderson NC, Mackinnon AC, Farnworth SL, Poirier F, Russo FP, Iredale JP, et al. Galectin-3 regulates myofibroblast activation and hepatic fibrosis. Proc Natl Acad Sci U S A. 2006 Mar; 103(13):5060-5. DOI: 10.1073/pnas.0511167103

49. Henderson NC, Mackinnon AC, Farnworth SL, Kipari $\mathrm{T}$, Haslett C, Iredale JP, et al. Galectin-3 expression and 
secretion links macrophages to the promotion of renal fibrosis. Am J Pathol. 2008 Feb; 172(2):288-98. DOI: 10.2353/ajpath.2008.070726

50. van Kimmenade RR, Januzzi JL, Jr., Ellinor PT, Sharma UC, Bakker JA, Low AF, et al. Utility of amino-terminal probrain natriuretic peptide, galectin-3, and apelin for the evaluation of patients with acute heart failure. J Am Coll Cardiol. 2006 Sep; 48(6):1217-24. DOI: 10.1016/j.jacc.2006.03.061

51. Edelmann F, Holzendorf V, Wachter R, Nolte K, Schmidt AG, Kraigher-Krainer E, et al. Galectin-3 in patients with heart failure with preserved ejection fraction: results from the Aldo-DHF trial. Eur J Heart Fail. 2015 Feb; 17(2):214-23. DOI: 10.1002/ejhf.203

52. Mueller T, Gegenhuber A, Leitner I, Poelz W, Haltmayer W, Dieplinger B. Diagnostic and prognostic accuracy of galectin-3 and soluble ST2 for acute heart failure. Clin Chim Acta. 2016 Dec; 463:158-64. DOI: 10.1016/j.cca.2016.10.034

53. Mohammed LA, Gafar HS, Hussien NR. Galectin-3 as Early Detector of Heart Failure in Children with Congenital Acyanotic Heart Disease. Clin Med Diagn. 2014: 4(5):90-8.

54. Tavazzi L, Maggioni AP, Marchioli R, Barlera S, Franzosi MG, Latini R, et al. Effect of rosuvastatin in patients with chronic heart failure (the GISSI-HF trial): a randomised, double-blind, placebo-controlled trial. Lancet. 2008 Oct; 372(9645):1231-9. DOI: 10.1016/ S0140-6736(08)61240-4

55. Rogers JK, Jhund PS, Perez AC, Böhm M, Cleland JG, Gullestad L, et al. Effect of rosuvastatin on repeat heart failure hospitalizations: the CORONA Trial (Controlled Rosuvastatin Multinational Trial in Heart Failure).JACC Heart Fail. 2014 Jun; 2(3):289-97. DOI: 10.1016/j.jchf.2013.12.007

56. Anand IS, Rector TS, Kuskowski M, Adourian A, Muntendam P, Cohn JN. Baseline and serial measurements of galectin- 3 in patients with heart failure: relationship to prognosis and effect of treatment with valsartan in the Val-HeFT. Eur J Heart Fail. 2013 May; 15(5):511-8. DOI: 10.1093/eurjhf/hfs205

57. Edelmann F, Holzendorf V, Wachter R, Nolte K, Schmidt AG, Kraigher-Krainer E, et al. Galectin-3 in patients with heart failure with preserved ejection fraction: results from the Aldo-DHF trial. Eur J Heart Fail. 2015 Feb; 17(2):214-23. DOI: 10.1002/ejhf.203

58. Pitt B, Pfeffer MA, Assmann SF, Boineau R, Anand IS, Claggett B, et al. Spironolactone for heart failure with preserved ejection fraction. N Engl J Med. 2014 Apr; 370(15):1383-92. DOI: 10.1056/NEJMoa1313731

59. AbouEzzeddine OF, Haines P, Stevens S, Nativi-Nicolau J, Felker GM, Borlaug BA, et al. Galectin-3 in heart failure with preserved ejection fraction. A RELAX trial substudy (Phosphodiesterase-5 Inhibition to Improve Clinical Status and Exercise Capacity in Diastolic Heart Failure). JACC Heart Fail. 2015 Mar; 3(3):24552. DOI: 10.1016/j.jchf.2014.10.009

60. Stolen CM, Adourian A, Meyer TE, Stein KM, Solomon SD. Plasma galectin-3 and heart failure outcomes in MADIT-CRT (multicenter automatic defibrillator implantation trial with cardiac resynchronization therapy). J Card Fail. 2014 Nov; 20(11):793-9. DOI: 10.1016/j.cardfail.2014.07.018

61. Milting H, Ellinghaus P, Seewald M, Cakar H, Bohms B, Kassner A, et al. Plasma biomarkers of myocardial fibrosis and remodeling in terminal heart failure patients supported by mechanical circulatory support devices. J Heart Lung Transplant. 2008 Jun; 27(6):58996. DOI: 10.1016/j.healun.2008.02.018

62. Erkilet G, Schulte-Eistrup S, Morshuis M, Bohms B, Roefe D, Gummert J, et al. Plasma galectin 3 is increased in terminal heart failure patients and is elevated in patients not surviving mechanical circulatory support. J Heart Lung Transplant. 2010 Feb; 29(2):S65. DOI: 10.1016/j.healun.2009.11.191

63. Coromilas E, Que-Xu EC, Moore D, Kato TS, Wu C, Ji R, et al. Dynamics and prognostic role of galectin-3 in patients with advanced heart failure, during left ventricular assist device support and following heart transplantation. BMC Cardiovasc Disord. 2016 Jun; 16:138. DOI: $10.1186 / \mathrm{s} 12872-016-0298-\mathrm{Z}$

64. Shah RV, Chen-Tournoux AA, Picard MH, van Kimmenade RR, Januzzi JL.Galectin-3, cardiac structure and function, and long-term mortality in patients with acutely decompensated heart failure. Eur J Heart Fail. 2010 Aug; 12(8):826-32. DOI: 10.1093/eurjhf/hfq091

65. Baldenhofer G, Zhang K, Spethmann S, Laule M, Eilers B, Leonhardt F, et al. Galectin-3 predicts short- and long-term outcome in patients undergoing transcatheter aortic valve implantation (TAVI). Int J Cardiol. 2014 Dec; 177(3):912-7. DOI: 10.1016/j.ijcard.2014.10.010

66. Felker GM, Fiuzat M, Shaw LK, Clare R, Whellan DJ, Bettari L, et al. Galectin-3 in ambulatory patients with heart failure: results from the HF-ACTION study. Circ Heart Fail. 2012 Jan; 5(1):72-8. DOI: 10.1161/CIRCHEARTFAILURE.111.963637

67. de Boer RA, van Veldhuisen DJ, Gansevoort RT, Muller Kobold AC, van Gilst WH, Hillege HL, et al. The fibrosis marker galectin-3 and outcome in the general population. J Intern Med. 2012 Jul; 272(1):55-64. DOI: 10.1111/j.1365-2796.2011.02476.x

68. Ho JE, Liu C, Lyass A, Courchesne P, Pencina MJ, Vasan RS, et al. Galectin-3, a marker of cardiac fibrosis, predicts incident heart failure in the community. J Am Coll Cardiol. 2012 Oct; 60(14):1249-56. DOI: 10.1016/j.jacc.2012.04.053 